This PDF is a selection from a published volume from the National Bureau of Economic Research

Volume Title: Health Care Issues in the United States and Japan

Volume Author/Editor: David A. Wise and Naohiro Yashiro, editors

Volume Publisher: University of Chicago Press

Volume ISBN: 0-262-90292-7

Volume URL: http://www.nber.org/books/wise06-1

Conference Date: May 1-3, 2003

Publication Date: September 2006

Title: Conjoint Analysis to Estimate the Demand for Nicotine Replacement Therapy in Japan

Author: Seiritsu Ogura, Wataru Suzuki, Makoto Kawamura, Tamotsu Kadoda

URL: http://www.nber.org/chapters/c7367 


\section{Conjoint Analysis to Estimate the Demand for Nicotine Replacement Therapy in Japan}

Seiritsu Ogura, Wataru Suzuki, Makoto Kawamura, and Tamotsu Kadoda

\subsection{Introduction}

Cigarette smoking is associated with such life-threatening illnesses as cancer, ischemic heart disease, cerebrovascular disease, and chronic lung disease. Smoking contributes not only to lung cancer but also to cancers of the pharynx, esophagus, bladder, and many others. It is reported that complications of pregnancy, including low birth weight and miscarriage, are related to smoking. Passive smoking is also a risk factor for such diseases. Cigarette smoking is one of the most serious causes of premature mortality in Japan. Researchers have estimated that about 113,400 Japanese die annually due to smoking-related illnesses, which accounts for 11.8 percent of total deaths (Peto et al. 2004). Estimates of excess medical costs per year due to smoking-related disease range from 1.2 trillion (Institute for Health Economics and Policy 1997) to 3.2 trillion yen (Goto 1995,1996$),{ }^{1}$ or from 5 to 15 percent of national medical expenditures.

In response to the escalating national health care costs, particularly those of lifestyle-related diseases, smoking cessation has become one of the most important national health policy objectives. The Ministry of Health, Labor and Welfare established the Committee on Tobacco Control for the 21 st Century in the year 2000 and was committed to a national no-

Seiritsu Ogura is a professor of economics at Hosei University and director general of the Hosei Institute on Aging. Wataru Suzuki is an assistant professor in the Department of Education at Tokyo Gakugei University. Makoto Kawamura is a professor of economics at Hosei University. Tamotsu Kadoda is an assistant professor of economics at Daito Bunka University.

1. It has been estimated that the total social loss including lost gross national product (GNP) as well as medical expenses amounted to between 4 trillion (Institute for Health Economics and Policy 1997) and 5.6 trillion yen (Goto 1995, 1996). 
smoking-week campaign. The ministry also established as an objective the provision of support to help smokers stop smoking in all communities. The Japanese Medical Association has also conducted an antismoking campaign since year 2001.

A significant proportion of smokers seriously consider quitting smoking. For example, according to the Survey on Smoking and Health Problems in 1998 by the Japanese government, 26.7 percent of current smokers aged fifteen and over want to quit smoking, and 64.2 percent of them want to quit smoking or cut down smoking. However, only a small fraction of them actually succeed on their own, due to the addictive nature of nicotine (U.S. Department of Health and Human Services 1988, 1995, 1996a; WHO 1993). Recently, however, smoking intervention programs, particularly those using nicotine replacement therapy (NRT), have been shown to be very effective in other countries, such as the United States.

Nicotine replacement therapy is a method of treatment that helps smokers by alleviating the withdrawal symptoms associated with smoking cessation by replacing the nicotine. Researchers have shown that 17 to 50 percent of smokers have succeeded in smoking cessation using those therapies (Momma 1998; Asano 2000; Wasley et al. 1997; Jorenby et al. 1999; Schneider, Jarvik, and Forsythe 1984). Two types of NRT products are available in Japan, nicotine transdermal patches and nicotine gum. Nicotine patches were approved by the Ministry of Health and Welfare in 1994, and nicotine gums were approved in 1999. Despite the effectiveness of those products, they have failed to come into wide use in Japan, as they have been available only by prescription, and their costs have not been covered by the public health insurance.

The government has done nothing to inform the smokers of the availability of NRT, and there were few medical professionals who could give counseling or other therapies for smoking cessation. Things changed completely in September 2001 when the Ministry of Health and Welfare, under the strong pressure to show concrete results of deregulation in health care sector, approved nicotine gum (brand name Nicorette) as an over-thecounter drug. There immediately followed an extensive nationwide campaign by the pharmaceutical company using TV, newspapers, and magazines. As a result, Nicorette is now widely recognized among smokers as well as nonsmokers.

In this paper, we estimate the demand for nicotine gum and examine the smoking cessation assistance policy with NRT using original survey data gathered by the authors in late 2001. Our analysis is the first attempt to estimate the demand for NRT in Japan. Tauras and Chaloupka (2001) assessed the impact of NRT prices and cigarette prices on NRT demand using pooled cross-sectional-time series data for fifty major metropolitan markets in the United States from 1996 to 1999. We could not employ a similar technique because panel data are not available in Japan; nicotine 
gum has been in the market for a relatively short period of time, and domestic cigarette prices are uniformly set throughout Japan. Therefore, we employed conjoint analysis (CA), a technique that is relatively new to the field of health economics.

Conjoint analysis is one of the techniques belonging to contingent valuation methods (CVM) used to estimate an individual's utilities from responses to hypothetical questions. Conjoint analysis was originally developed in the field of market research and psychometrics. It has been widely used in environmental economics and transport economics, and it has been introduced into health economics. ${ }^{2}$ In Japan, CA has been used to estimate the demand for nursing care (Suzuki and Okusa 1999), the choice of medical facilities (Fukuda et al. 1999), and the demand for medical care for minor illness (Suzuki and Okusa 2000).

The stages of CA are detailed as follows. First, hypothetical scenarios and discrete choice questionnaires are presented to individuals. After individuals state their preference, the responses are used to determine utilities. A statistical model is constructed using the hypothetical scenarios and the characteristics of respondents as explanatory variables and stated preferences as the dependent variable. Then the utility function and rate of substitution are calculated.

The methodologies commonly utilized to assess individuals' utilities in health economics have been the standard gamble, time trade-off, and rating scale as well as willingness to pay. These traditional approaches have both theoretical and technical problems. The price obtained from willingness to pay does not properly reflect the real utility level. None of usual approaches - standard gamble, time trade-off, and rating scale - can capture the utility level very well. When we deal with ordinal utility, it can be problematic to compare and add up utility levels among individuals. Unlike these four techniques, CA uses questionnaires asking individuals about their relative preferences instead of directly asking their utility level. Therefore, it can avoid the problem faced by the other methods. Conjoint analysis is also advantageous in that unobservable factors related to the individual can be eliminated as an individual effect.

The remainder of the paper is organized as follows. In section 10.2, the data used for this study are described. Descriptive statistics regarding smoking and awareness of nicotine gum are also provided in this section. In section 10.3, the methods and results using CA are presented. The application of the estimates from CA to cost-benefit analysis is demonstrated in section 10.4. We compare the costs and benefits of a hypothetical subsidy for nicotine gum. Section 10.5 concludes.

2. For examples, see Bryan et al. (1998), Freeman (1998), Hakim and Pathak (1999), Ratcliffe and Buxton (1999), Ryan (1999), Ryan and Farrar (1994), Ryan and Hughes (1997), Singh et al. (1998), and Van der Pol and Cairns (1997). 


\begin{tabular}{lrrrrr}
\hline & $N$ & Mean & $\begin{array}{r}\text { Standard } \\
\text { deviation }\end{array}$ & Minimum & Maximum \\
\hline Age of smoking initiation & 499 & 20.68136 & 5.032891 & 12 & 60 \\
Years of smoking & 499 & 20.28858 & 12.45703 & 0 & 50 \\
Level of nicotine dependence & & & & & \\
$\quad$ FTND index) & 501 & 4.966068 & 2.199283 & 1 & 11 \\
Sex & 501 & 0.6267465 & 0.484152 & 0 & \\
Age & 501 & 41.00399 & 13.24915 & 20 & 69 \\
Education & 501 & 0.491018 & 0.500419 & 0 & 1 \\
Annual income & 487 & 692.7618 & 399.5757 & 50 & 2000 \\
Logged annual income & 487 & 6.357238 & 0.6582189 & 3.912023 & 7.600903 \\
Number of family & 498 & 3.210843 & 1.484231 & 1 & 12 \\
Hcart disease & 501 & 0.0279441 & 0.1649775 & 0 & 1 \\
Diabetes & 501 & 0.0299401 & 0.1705925 & 0 & 1 \\
Disease of circulatory system & 501 & 0.0578842 & 0.2337578 & 0 & 1 \\
Disease of digestive system & 501 & 0.0798403 & 0.2713167 & 0 & 1 \\
\hline
\end{tabular}

Notes: Years of smoking is derived by subtracting age of smoking started from current age. The FTND index is an epidemiological index that measures the level of nicotine dependence (see note in the paper). Annual income is in ten thousands of yen. Education was coded 1 if finished postcollegiate, college, or junior college, 0 otherwise. Each chronic illness was coded 1 if there is any, 0 otherwise.

Table 10.2

Desire for smoking cessation

\begin{tabular}{lrr}
\hline & $N$ & Percent \\
\hline In the process & 36 & 7.2 \\
Want to but haven't done anything & 239 & 47.7 \\
Don't want to quit & 226 & 45.1 \\
\hline
\end{tabular}

\subsection{Data}

The data were collected using the Survey on Smoking that the authors conducted in November 2001. The questionnaire was mailed to 500 smokers aged twenty to sixty-nine who were residing in the Tokyo metropolitan area. They were selected from a list of monitors who had registered with a private research firm. The firm randomly selected their monitors from a national resident-registry list. ${ }^{3}$ The response rate was 83.3 percent. The characteristics of individuals included in the analysis are presented in table 10.1.

The survey asked the respondents about their attitude toward and awareness of smoking cessation and nicotine gum before presenting the hypothetical scenarios. Table 10.2 indicates the attitude toward smoking ces-

3. It is possible that sample bias arose when people decided whether to be a monitor, but the social research firm made efforts to make the bias as small as possible by adjusting the sample to represent the census distribution in terms of age and other characteristics. 


\begin{tabular}{|c|c|c|c|c|}
\hline & \multicolumn{2}{|c|}{$\begin{array}{l}\text { Smokers who } \\
\text { want to quit }\end{array}$} & \multicolumn{2}{|c|}{$\begin{array}{l}\text { Smokers who } \\
\text { attempted smoking } \\
\text { cessation }\end{array}$} \\
\hline & $N$ & Percent & $N$ & Percent \\
\hline Don't use anything & 198 & 72.5 & 27 & 75.0 \\
\hline $\begin{array}{l}\text { Counseling by } \\
\text { medical professionals }\end{array}$ & 0 & 0.0 & & \\
\hline Nicorette & 63 & 23.1 & 8 & 22.2 \\
\hline Other & 12 & 4.4 & 1 & 2.8 \\
\hline
\end{tabular}

Table 10.4

Recognition of Nicorette

\begin{tabular}{lll}
\hline & $N$ & Percent \\
\hline Know of Nicorette & 350 & 70.14 \\
Don't know of Nicorette & 149 & 29.86 \\
\hline
\end{tabular}

Table 10.5

Opinion of the price of Nicorette

\begin{tabular}{lrr}
\hline & $N$ & Percent \\
\hline Expensive & 398 & 79.8 \\
Appropriate & 89 & 17.8 \\
Inexpensive & 12 & 2.4 \\
\hline
\end{tabular}

sation among smokers. Of particular interest is the fact that 7 percent of smokers were attempting to quit, and 48 percent were contemplating quitting. Thus, more than half of smokers in our sample want to quit smoking. The methods of smoking cessation are presented in table 10.3. Among the smokers who want to quit smoking, a large majority of them ( 72.5 percent) did not plan to use any particular device or help, but almost one-quarter (23.1 percent) of them mentioned nicotine gum as a device. There were eight respondents who were actually using the nicotine gum, which represents 22.2 percent of those who were actually trying to quit smoking. Table 10.4 shows that already 70.1 percent of respondents were aware of the nicotine gum, and it is clear that the nicotine gum has become widely known, at least in the Tokyo metropolitan area, in a very short period of time after it was introduced into the market. However, nearly 80 percent of respondents viewed Nicorette as expensive, as table 10.5 shows. ${ }^{4}$ As a result, only

4. The price was 6,900 yen for sixty pieces and 36,000 yen for a course of smoking cessation. The authors estimated the cost of a course of smoking cessation based on the directions for use and the price from Nicorette's homepage (http://www.nicorette-j.com/). 
13.5 percent of respondents were willing to use nicotine gum (table 10.6). We also asked for the reason they were not going to use the gum among those who answered "interested but won't use" or "not interested." About 50 percent of them answered that the nicotine gum was expensive. This suggests that the high price is preventing the diffusion of the nicotine gum.

\subsection{Estimation of Demand for Nicotine Gum}

\subsubsection{Estimation Model}

The questionnaires used for $\mathrm{CV}$ are presented in table 10.7. Respondents were asked to circle 1 or 2 for each scenario, which indicated "use nicotine gum" and "not use nicotine gum," respectively. The factors that varied across scenarios were the price of nicotine gum, the price of cigarettes, and access to nicotine gum. Several levels were assigned for each attribute. Two different prices were assigned for the nicotine gum: its current price and half the current price. Three different prices were assigned for cigarettes: the current price, double the current price, and five times the current price. Two levels of access were used: status quo and being able to get the gum at

Table 10.6

Interest in Nicorette

\begin{tabular}{lrc}
\hline & $N$ & Percent \\
\hline Want to use & 67 & 13.5 \\
Interested but won't use soon & 241 & 48.5 \\
Not interested & 189 & 38.0 \\
\hline
\end{tabular}

Table 10.7

Hypothetical scenarios

If Nicorette is sold at half-price (3,450 yen for 60 tablets; 18,000 yen for a course of smoking cessation)

If Nicorette is sold at half-price and available at a vending machine or at a convenience store

If Nicorette is sold at half-price while tobacco price is doubled (about 500 yen a box)

If Nicorette is sold at half-price while tobacco price is raised to five times as much as current price

If Nicorette is sold at half-price and available at a vending machine or at a convenience store while tobacco price is raised to five times as much as current price

If Nicorette's price stays the same $(6,900$ yen for 60 tablets; 3,600 yen for a course of smoking cessation) but available at a vending machine or at a convenience store

If Nicorette's price stays the same while tobacco price is doubled

If Nicorette's price stays the same while tobacco price is raised to five times as much as current price

If Nicorette's price stays the same and Nicorette is available at a vending machine or at a convenience store while tobacco price is doubled

If Nicorette's price stays the same and Nicorette is available at a vending machine or at a convenience store while tobacco price is raised to five times as much as current price 
a vending machine or at a convenience store. The combination of attributes and levels resulted in eleven possible scenarios $(2 \times 3 \times 2-1)$.

The estimation equation is as follows:

$$
\begin{aligned}
& G_{i, k}^{*}=\alpha_{0}+\alpha_{P} P_{i, k}+\alpha_{T} T_{i, k}+\alpha_{R} R_{i, k}+\alpha_{F} F_{i}+\alpha_{Y} Y_{i}+\alpha_{S} S_{i}+\alpha_{A} A_{i}+\alpha_{E} E_{i} \\
& +\alpha_{I} \log I_{i}+\alpha_{J} \sum_{l} \mathbf{J}_{i, l}+v_{i, k} \\
& G_{i, k}=\left\{\begin{array}{lll}
1 & \text { if } & G_{i, k}^{*}>0 \\
0 & & \text { otherwise }
\end{array}\right. \\
& v_{i, k}=\varepsilon_{i, k}+u_{i},
\end{aligned}
$$

where $G_{i, k}^{*}$ is a latent variable, which is a difference between the utility from quitting smoking with the nicotine gum and the utility from keeping smoking without it. Explanatory variables were defined as follows: $P_{i, k}$ is price of nicotine gum; $T_{i, k}$ is price of cigarettes; $R_{i, k}$ represents whether nicotine gum is available at a vending machine or at a convenience store ( 1 if available, 0 otherwise); $F_{i}$ is the FTND index ${ }^{5} Y_{i}$ is years of smoking; $A_{i}$ is age; $S_{i}$ is sex ( 1 if male, 0 if female); $E_{i}$ is categorized years of education ( 1 if junior college or more, 0 otherwise); $\log I_{i}$ is logged annual income; $\mathbf{J}_{i, t}$ is a vector of chronic illnesses ( 1 if they have, 0 otherwise); and $H_{i}$ is health status ( 1 if in bad health, 0 otherwise). We employed a random effect probit model (Butler and Moffitt, 1982) because we assumed that an individual had consistent effects regardless of scenarios. We assumed that the individual effect, $u_{i}$, was normally distributed as follows:

$$
u_{i} \sim N\left(0, \sigma_{u}^{2}\right)
$$

\subsubsection{Results}

Table 10.8 reports the results of the estimation. The coefficients of the three policy instruments had the expected signs. The price of nicotine gum had a negative effect on nicotine gum purchase, the price of cigarettes had a positive effect, and access to the gum had positive effects on nicotine gum purchase. Other statistically significant explanatory variables were the Fagerstrom Test for Nicotine Dependence (FTND) index, years of smoking, sex, education, log of annual income, and circulatory illness. The higher FTND index made the nicotine gum demand higher. The more years of smoking, the higher the demand for the gum. Women, people with higher income, and people with higher levels of education had higher de-

5. The nicotine dependence index developed by Dr. Fagerstrom was derived from a short paper-and-pencil test (Fagerstrom and Schneider 1989). We employed a revised Fagerstrom Test for Nicotine Dependence index (FTND index) for this study. The actual test is presented in the appendix. 


\begin{tabular}{lccc}
\hline & Coefficient & $\begin{array}{c}\text { Standard } \\
\text { error }\end{array}$ & $p$-value \\
\hline Nicorette price & $-0.8379^{* * *}$ & 0.0340 & 0.000 \\
Tobacco price & $0.0021^{* * *}$ & 0.0001 & 0.000 \\
Vending machine or convenience store & $0.1668^{* * *}$ & 0.0517 & 0.001 \\
FTND index & $0.2938^{* * *}$ & 0.0260 & 0.000 \\
Years of smoking & $-0.023^{* *}$ & 0.0095 & 0.016 \\
Sex & $-0.6523^{* * *}$ & 0.1152 & 0.000 \\
Age & 0.0006 & 0.0086 & 0.944 \\
Education & $0.1935^{*}$ & 0.1099 & 0.078 \\
Logged income & $0.2920^{* * *}$ & 0.0870 & 0.001 \\
Heart disease & -0.0812 & 0.2159 & 0.707 \\
Diabetes & -0.2906 & 0.2145 & 0.176 \\
Disease of circulatory system & $1.0400^{* * *}$ & 0.3642 & 0.004 \\
Disease of digestive system & 0.0424 & 0.1489 & 0.776 \\
Constant & $-3.0500^{* * *}$ & 0.5361 & 0.000 \\
\hline
\end{tabular}

Notes: Nicorette price is in 10,000 yen, and tobacco price is in yen. The number of total samples is 5,820 (485 individuals are included). $\log$ likelihood $=-2065.8625$.

$* * *$ Significant at the 1 percent level.

** Significant at the 5 percent level.

*Significant at the 10 percent level.

mand for nicotine gum. People with circulatory disease also had higher demand.

Table 10.9 shows the marginal effect of each attribute. The results indicate that a 10,000 yen ( 27.8 percent) decrease in the price of nicotine gum would increase its own demand by 16.5 percent, and a 100 yen ( 40.0 percent) increase in the price of cigarettes would lead to an increase of 4.2 percent in the demand for nicotine gum. It is also revealed that if nicotine gum is made available at a vending machine or a convenience store, the demand for the gum would increase by 3.3 percent.

Our estimation results are basically consistent with the findings of Tauras and Chaloupka (2001) that show that the price of nicotine gum has a negative effect on its demand, while the price of cigarettes has a positive effect. ${ }^{6}$ Specifically, using pooled cross-sectional-time-series observational data for fifty major metropolitan markets in the United States, Tauras and Chaloupka showed that the average own-price elasticity of demand for nicotine gum is -1.5 , while the average cross-price elasticity for cigarettes is 0.81 , which is several times larger in magnitude than our estimates of -0.59 and 0.11 , respectively. These differences in price elasticities could be

6. Keeler et al. (2002), however, find that the impact of the price of nicotine gum on demand is not statistically significant in the United States. 
Table 10.9 Marginal effects

\begin{tabular}{|c|c|c|c|}
\hline & Coefficient & $\begin{array}{c}\text { Standard } \\
\text { error }\end{array}$ & $p$-value \\
\hline Nicorette price & $-0.1652^{* * *}$ & 0.0121 & 0.000 \\
\hline Tobacco price & $0.0004^{* *}$ & 0.0000 & 0.000 \\
\hline Vending machine or convenience store & $0.0329^{* * *}$ & 0.0104 & 0.002 \\
\hline FTND Index & $0.0579^{* * *}$ & 0.0060 & 0.000 \\
\hline Years of smoking & $-0.0045^{* *}$ & 0.0018 & 0.015 \\
\hline $\operatorname{Sex}^{\mathrm{a}}$ & $-0.1419^{* * *}$ & 0.0274 & 0.000 \\
\hline Age & 0.0001 & 0.0017 & 0.944 \\
\hline Education ${ }^{2}$ & $0.0383^{*}$ & 0.0222 & 0.086 \\
\hline Logged income & $0.0576^{* * *}$ & 0.0171 & 0.001 \\
\hline Heart disease ${ }^{a}$ & -0.0153 & 0.0389 & 0.694 \\
\hline Diabetes & -0.0484 & 0.0299 & 0.105 \\
\hline Disease of circulatory system ${ }^{a}$ & $0.3113^{* *}$ & 0.1377 & 0.024 \\
\hline Disease of digestive system & 0.0085 & 0.0305 & 0.780 \\
\hline
\end{tabular}

Note: Nicorette price is in 10,000 yen, and tobacco price is in yen. Standard errors are calculated by Delta method.

${ }^{a} \mathrm{dy} / \mathrm{dx}$ is for discrete change of dummy variable from 0 to 1 .

***Significant at the 1 percent level.

**Significant at the 5 percent level.

*Significant at the 10 percent level.

due to the difference in the nature of the data used for the analyses; where they use aggregate market data, we use microconjoint data.

\subsection{Cost-Benefit Analysis for a Smoking Cessation Support Policy}

Nicotine replacement therapy is costly to the individual because it is not paid for by health insurance, whether it is prescribed or purchased over the counter. We examine whether a government subsidy for nicotine gum would make NRT more available to people who want to quit smoking.

Many epidemiological studies have shown that among ex-smokers, disease incidence decreases dramatically up until five years after smoking cessation and continues to drop thereafter, eventually reaching the same level as nonsmokers after ten to fifteen years (U.S. Department of Health and Human Services 1990, 1996b; Hirayama 1987; Hirayama 1990). If the benefits from smoking cessation go only to smokers, they should be responsible for all the costs associated with NRT. However, Japan has a universal health insurance system, which covers 70 percent of medical expenses, and the nation as a policyholder shares the cost of supporting the health insurance system. If nicotine gum helps to reduce national medical expenditures and health insurance payments, the benefits are considered externalities. In such a case, it could make sense to introduce a subsidy for the nicotine gum. Specifically, we wish to examine how the costs of a sub- 
Total costs

Total cost $=$ A (Subsidy per capita) $\cdot$ B (Increased number of smokers who demand the gum after the policy)

$A=$ Average cost for a course of smoking cessation $\cdot$ Subsidy rate $(70 \%)$

$\mathrm{B}=\mathrm{C}$ (Estimated number of smokers) $\cdot \mathrm{D}$ (Increased demand ratio due to the policy)

$\mathrm{D}=$ Estimated demand elasticity $(0.16) \cdot \mathrm{A}$

Yearly benefits

Yearly benefits $=\mathrm{E}$ (Number of smokers who would succeed in smoking cession with policy)

- F (Reduced annual insurance payment)

$\mathrm{E}=\mathbf{B} \cdot$ Success rate by nicotine gum

$\mathrm{F}=\mathrm{G}$ (Excess health insurance payment per smoker) $\cdot \mathbf{H}$ (Rate of medical expense reduction by smoking cessation)

$\mathrm{G}=$ Excess annual medical expenditure due to smoking $\cdot$ Health insurance coverage rate $(0.7) / \mathrm{C}$

$H=($ Mortality of smokers - Mortality of former smokers)/(Mortality of smokers - Mortality of nonsmokers $)=($ Excess mortality of smokers Excess mortality of former smokers)/Excess mortality of smokers

Note: Average cost for a course of smoking cessation: 36,000 yen (authors' calculations based upon an explanatory note on the product). Subsidy rate: 0.7 . Estimated number of smokers: 33.6 millions (Ministry of Health and Welfare 1999). Estimated price elasticity of demand: 0.16 (table 10.8). Excess annual medical expenditure due to smoking: 1.2 trillion yen (Institute for Health Economics and Policy 1997). Health insurance coverage rate: 0.7. Success rate by nicotine gum: 23\% (Asano 2000). Excess mortality of smokers: $23 \%$ (Hirayama 1987).

sidy compare to the benefits associated with a reduction in health insurance payments.

Therefore, we have estimated the costs and the benefits associated with the subsidy policy and conducted a cost-benefit analysis. We assumed the subsidy rate to be 70 percent. This was appropriate because if the nicotine gum is covered with health insurance, the coverage rate would be 70 percent. ${ }^{7}$ Equations for costs and benefits are presented in table 10.10 .

\subsubsection{Total Cost}

The total cost was calculated by multiplying the subsidy per smoker by the increased number of smokers who demand the nicotine gum due to the policy. The subsidy per smoker is the product of the average cost for a course of smoking cessation ( 36,000 yen) and subsidy rate (70 percent). The increased number of smokers demanding the nicotine gum after the policy is the product of the estimated number of smokers and increased demand ratio due to the policy (equation [3]). The increased demand ratio due to the policy was derived from the estimates presented in table 10.8 . According to the CA results, a 10,000 yen downward shift in the price of a

7. Our assumption is not that insurance coverage would pay 70 percent of the cost, but rather that a subsidy would reduce the price to 30 percent of the current price. 
course of treatment is to reduce the demand response by 16 percent. The cost reduction due to the subsidy was 25,200 yen $(36,000$ yen $\times 0.7)$. Therefore, the increased demand ratio due to the policy was 0.40 (D in table 10.10).

\subsubsection{Yearly Benefit}

The yearly benefit is a product of the number of smokers who succeeded in quitting smoking after the policy and the reduced annual insurance payments due to the policy (E $\cdot \mathrm{F}$ in table 10.10). The number of smokers who succeeded in quitting smoking after the policy is derived by multiplying the increased number of smokers demanding the nicotine gum after the policy by the success rate for smoking cessation with the nicotine gum ( $\mathrm{E}$ in table 10.10). The success rate used in this estimation was 23 percent, which is the mean value from epidemiological studies conducted in Japan (Asano 2000). It is conservative compared to other studies on NRT. The reduced annual insurance payment is, as $\mathrm{F}$ in table 10.10 shows, the product of the excess health insurance payment per smoker and the rate of medical expense reduction from smoking cessation. The excess health insurance payment per smoker was derived by dividing the product of excess annual medical expenditure due to smoking (1.2 trillion yen) and health insurance coverage rate $(0.7)$ by the estimated number of smokers ( 33.6 millions). The 1.2 trillion yen as excess annual medical expenditures is quite moderate, and the actual insurance coverage rate is more than 70 percent. Therefore, the values we used are considered very conservative. We multiplied excess health insurance payment per smoker by the rate of medical expense reduction rate due to smoking cessation in order to adjust the effect of smoking cessation on medical expenses, which was not exactly the same as among nonsmokers. According to Hirayama's study (1987), excess mortality of smokers and excess mortality of former smokers were 23 percent and 4 percent, respectively. We employed these numbers. We divided the difference between 23 percent and 4 percent by 23 percent, then obtained the rate of medical expense reduction due to smoking cessation, which is 82 percent.

\subsubsection{Cost-Benefit}

Consequently the subsidy would cost the government a total of 352.4 billion yen, and the benefits due to the reduction of health insurance payment would be 67.6 billion yen per year. The benefits would be ongoing even if the subsidy were offered only once. After five years, the government would be able to save 338.5 billion yen ( 67.6 billion $\times 5$ ), which is approximately equal to the cost. Given that the benefits could continue for longer than five years, it is highly possible that the benefits of the subsidy policy could meet all of the costs.

\subsubsection{Other Factors to Be Considered as Long-Run Effects}

The cost-benefit analysis in this section was conducted with very limited information, so it cannot be overemphasized that various other factors 

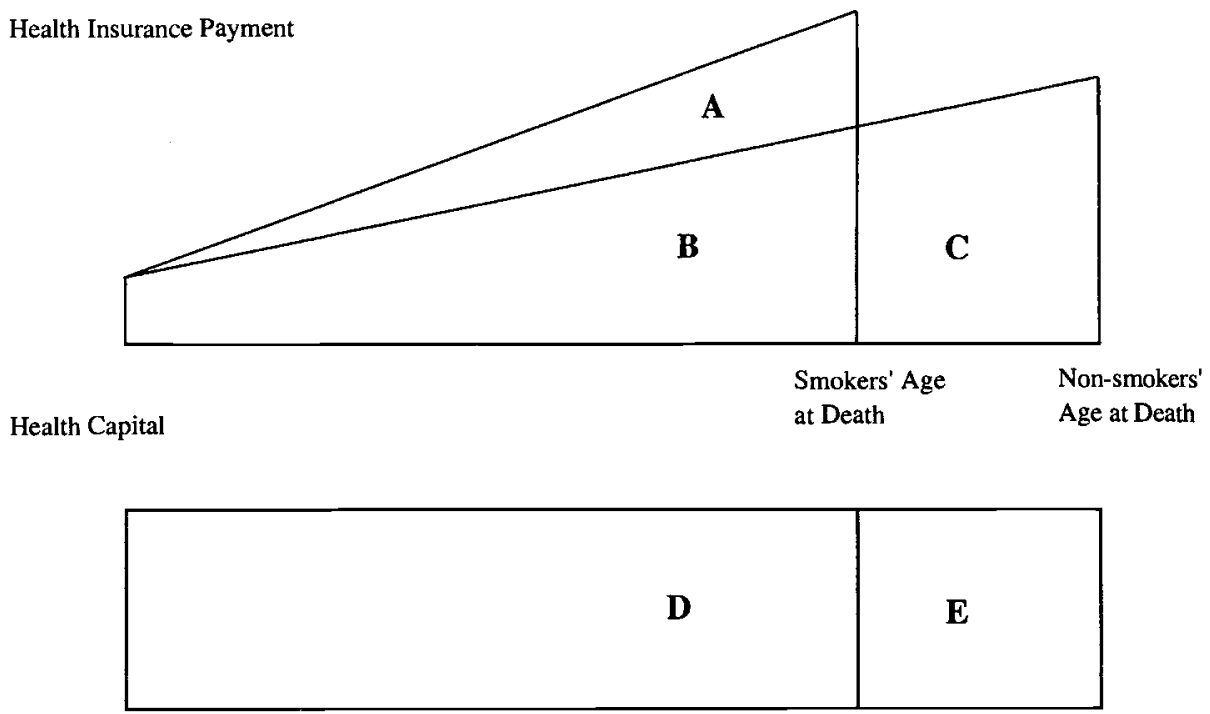

$\begin{array}{ll}\text { Smokers' Age } & \text { Non-smokers' } \\ \text { at Death } & \text { Age at Death }\end{array}$

Fig. 10.1 Lifetime health insurance payment and health capital by smoking status

should be taken into consideration for a more precise analysis. One of the most important factors is the part of the health insurance payment corresponding to the life extended by smoking cessation. The concept is shown in the upper part of figure 10.1. It illustrates the insurance payment that increases with age. The lifetime insurance payments of smokers are shown by the area of $\mathrm{A}+\mathrm{B}$. The area of $\mathrm{B}$ is an insurance payment that is common to both smokers and nonsmokers, and the area of A is a smoker's additional health insurance payment due to health problems. The decrease in the area of A due to smoking cessation represents cost savings. On the other hand, the area of $\mathrm{C}$ would be added to costs when the length of life is extended. Therefore, net benefits should be calculated by subtracting the area of $\mathrm{C}$ from the area of $\mathrm{A}$.

In order to compute the area of $\mathrm{C}$, two numerical values are required. One is the difference between the average life expectancy among smokers versus nonsmokers. The other is medical expenses associated with longevity. The first number is, unfortunately, unavailable in Japan, but it has been estimated in various countries. The median longevity effect is eight years (Simpson 2000), and we used this number. As for the extra medical expense, it is not overwhelming according to the research by Suzuki and

8. Suzuki and Suzuki (2003) decomposed the medical expenses for the aged into the ordinal care and the terminal care as Lubitz, Beebe, and Baker (1995) did. 
Suzuki (2003). ${ }^{8}$ Living eight more years makes medical expenses increase only by 3.94 million yen per person because most of the medical expenditure for the old is accounted for by terminal care. We multiplied this 3.94 million yen increase in the insurance payment by 78 million people, which is the number of successful ex-smokers, and obtained the cost presented in the area of $\mathrm{C}$, which is 3,073 billion yen.

The other possible benefit is the increased health capital due to longevity (see figure 10.1). Health capital is a monetary value of life that takes health into consideration. It is defined as follows:

$$
\text { health capital }=V \sum_{k=0}^{\infty} \frac{E\left(H_{k}\right)}{(1+r)^{k}},
$$

where $V$ is the value of the life, which is normally lifetime earnings. $H_{k}$ is quality of life factor for a year at age $k$; and $r$ is real discount rate. The value of health capital was estimated by Cutler and Richardson $(1997,1998)$ in the United States and by Fukui and Iwamoto (2003) in Japan. We can take sum of the implied quality of life age factor from Fukui and Iwamoto (2003) and lifetime earnings (280 million yen) from the Economic Surveys of Japan in 1990. Using a 3 percent real discount rate, like Cutler and Richardson, the benefit associated with an eight-year increase in health capital was 8.54 million yen per person. We multiplied the 8.54 increase in health capital by 78 million people and obtained the benefit represented by the area of $E$, which is 6,670 billion yen. As a result, the area of $C$ subtracted from $\mathrm{E}$, which is the net benefit associated with the lengthened life, amounts to 3,300 billion yen.

\subsection{Conclusions}

This paper estimates the demand function for nicotine gum (Nicorette) that has been on the market since it was approved as an over-the-counter drug in September 2001. The estimate obtained from conjoint analysis indicates that a 10,000 yen decrease in the price of nicotine gum would increase the demand for the gum by 16.5 percent, and a 100 yen increase in the price of cigarettes would lead to an increase in the demand for nicotine gum of 4.2 percent. It is also estimated that if nicotine gum were made available at a vending machine or a convenience store, the demand for nicotine gum would increase by 3.3 percent.

A cost-benefit analysis was conducted to estimate the consequence of a subsidy policy for nicotine gum. In the case of a 70 percent subsidy for nicotine gum, it would cost the government 352.4 billion yen. The benefits associated with the subsidy are a decrease in smoking-related illnesses through successful smoking cessation. This would make annual medical insurance payment fall by 67.6 billion yen. After five years, the government would save 338.5 billion yen, which is comparable to the cost. 
When we take the change in the lifetime medical insurance payments and health capital accumulation into account, 3,300 billion yen should be added to the benefits in the long run.

The Ministry of Health, Labor and Welfare initiated the national health promotion movement so-called Healthy Japan 21 in the year 2000 and established smoking cessation promotion as one of the most important policy objectives. A subsidy for nicotine gum or insurance coverage for the gum is one possible means of achieving the public health goal.

It is worth noting that the costs and benefits that this study used were based on a demand function estimated using $\mathrm{CA}$, which does not necessarily represent the actual demand function. ${ }^{9}$ The net values of CBA should, therefore, be carefully examined. Furthermore, when real transaction data eventually become available, the demand function should be calculated with the real values, and the total costs and benefits should be reexamined.

\section{Appendix}

Table 10A.1

Fagerstrom Test for Nicotine Dependence Index

\begin{tabular}{llc}
\hline Questions & \multicolumn{1}{c}{ Answers } & Points \\
\hline $\begin{array}{l}\text { 1. How soon after you wake up do you } \\
\text { smoke your first cigarette? }\end{array}$ & Within 5 minutes & 3 \\
& Within 6-30 minutes & 2 \\
& Within 31-60 minutes & 1 \\
2. Do you find it difficult to refrain from & After 60 minutes & 0 \\
smoking in places where it is forbidden? & No & 1 \\
(e.g., in library, in movie theater) & & 0 \\
3. Which cigarette would you most hate & The first one in the morning & 1 \\
to give up? & Any other & 0 \\
4. How many cigarettes a day do you smoke? & 31 or more & 3 \\
& $21-30$ & 2 \\
& $11-20$ & 1 \\
& 10 or more & 0 \\
5. Do you smoke more frequently during & Yes & 1 \\
the first hours after awakening than during & No & 0 \\
the rest of the day? & & 1 \\
6. Do you smoke if you are so ill that you & Yes & 0 \\
are in bed most of the day? & No & \\
\hline
\end{tabular}

9. Suzuki and Okusa (2000) evaluated the magnitude of the bias in CA by comparing the demand function from $\mathrm{CA}$ to the actual demand function calculated from transaction data. Tsuji and Suzuki (2002) measured the bias in CVM. Conjoint analysis has relatively small bias compared to other hypothetical market methods, but there is still a discrepancy with the real value. Further research should explore methods to lessen the bias. 


\section{References}

Asano, M. 2000. Kitsuen to kinen [Smoking and smoking cessation]. Nihon Kinen Suishin Ishi-shikaishi Renmei Tushin 3:1-3.

Bryan, S., M. Buxton, R. Sheldon, and A. Grant. 1998. The use of magnetic resonance imaging for the investigation of knee injuries: A discrete choice conjoint analysis exercise. Health Economics 7:595-604.

Butler, J., and R. Moffitt. 1982. A computationally efficient quadrature procedure for the one factor multinominal probit model. Econometrica 50:347-64.

Cutler, D., and E. Richardson. 1997. Measuring the health of the United States population. Brookings Papers on Economic Activity, Microeconomics: 217-71. 97-100.

Fagerstrom, K. O., and N. G. Schneider. 1989. Measuring nicotine dependence: A review of the Fagerstrom Tolerance Questionnaire. Journal of Behavioral Medicine 12 (2): 159-82.

Freeman, J. 1998. Assessing the need for student health services using maximum difference conjoint analysis. Journal of Research in Pharmaceutical Economics 9 (3): $35-49$.

Fukuda, K., H. Kinoshita, S. Takemura, and S. Hachimaki. 1999. Kanja no iryokikan senkou ni kansuru conjoint analysis wo mochiita chosa kenkyu [Analysis of patients' decision to choose medical facilities using conjoint analysis]. Paper presented at the annual meeting of the Japan Hospital Management Association. October, Chiba, Japan.

Fukui, T., and Y. Iwamoto. 2003. Medical spending and the health outcome of the Japanese population. Paper presented at the 2003 spring meeting of the Japanese Economic Association. June, Oita, Japan.

Goto, K. 1995. Kankyo-keizai to korekara no sangyo-shakai [Environmental economic and future industrial society]. Chuo Koron 47:125-36.

1996. Tobacco no keizei bunseki [Economic analysis of tobacco]. Nohon Ishikai Zasshi 116:370-71.

Hakim, A., and D. Pathak. 1999. Modelling the EuroQol data: A comparison of discrete choice conjoint and conditional preference modelling. Health Economics 8:103-16.

Hirayama, T. 1987. Yobo gan gaku [A study of cancer prevention]. Tokyo: Medikaru Saiensusha.

1990. Lifestyle and mortality: A large-scale census based cohort study in Japan, Vol. 6 of Contributions to epidemiology and biostatistics. Basel, Switzerland: Karger.

Institute for Health Economics and Policy. 1997. Heisei 6-8 nendo kosei kagaku kenkyuhi hojo jigyo ni yoru kitsuen seisaku no cost-benefit bunseki ni kakawaru chosa kenkyu houkokusho [A report on cost-benefit analysis of smoking cessation policy]. Tokyo: Institute for Health Economics and Policy.

Jorenby, D. E., S. J. Leischow, M. A. Nides, S. I. Rennard, J. A. Johnston, A. R. Hughes, S. S. Smith et al. 1999. A controlled trial of sustained-release buyproprion, a nicotine patch, or both for smoking cessation. New England Journal of Medicine 340:685-91.

Keeler, T. E., T. W. Hu, A. Keith, R. Manning, M. D. Marciniak, M. Ong, and H. Y. Sung. 2002. The benefits of switching smoking cessation drugs to over-thecounter status. Health Economics 11:389-402.

Lubitz, J., J. Beebe, and C. Baker. 1995. Longevity and Medicare expenditure. The New England Journal of Medicine 332:999-1003. 
Ministry of Health and Welfare. 1999. Survey on smoking and health conditions. Tokyo: Ministry of Health and Welfare.

Momma, Y. 1998. Nikochin chikan ryoho ni yoru kitsuen no seiseki [Performance of smoking cessation using nicotine replacement therapy]. Journal of the American Medical Association (Japanese ed.): August: 62-63.

Peto, R., A. D. Lopez, J. Boreham, and M. Turn. 2004. Mortality from smoking in developed countries: 1950-2000. 2nd ed. Oxford, UK: Oxford University Press.

Ratcliffe, J., and M. Buxton. 1999. Patients' preferences regarding the process and outcomes of life saving technology: An application of conjoint analysis to liver transplantation. International Journal Technological Assessment Health Care 15 (2): $340-51$.

Ryan, M. 1999. Using conjoint analysis to take account of patient preferences and go beyond health outcomes. An Application to In-Vitro Fertilization, Social Science and Medicine 48:535-46.

Ryan, M., and S. Farrar. 1994. A pilot study using conjoint analysis to establish the views of users in the provision of orthodontic services in grampian. Health Economics Research Unit Discussion Paper no. 07/94. Aberdeen, UK: University of Aberdeen.

Ryan, M., and J. Hughes. 1997. Using conjoint analysis to assess women's preference for miscarriage management. Health Economics 6:261-74.

Schneider, N. G., M. E. Jarvik, and A. B. Forsythe. 1984. Nicotine vs. placebo gum in the alleviation of withdrawal during smoking cessation. Addictive Behaviors $9: 149-56$.

Singh, J., L. Cuttler, M. Shin, J. Silvers, and D. Neuhauser. 1998. Medical decisionmaking and the patient: Understanding preference patterns for growth hormone therapy using conjoint analysis. Medical Care 36 (8): AS31-AS45.

Suzuki, W., and Y. Okusa. 1999. Conjoint analysis wo mochiita kaigo juyo kansu no suitei [An estimation of long-term-care demand]. ISER Discussion Paper no. 486. Osaka, Japan. Institute of Social and Economic Research.

2000. Iryo juyo kodo no conjoint analysis [Conjoint analysis for the demand of health care related to common cold]. Iryo to Shakai 10 (1): 125-44.

Suzuki, W., and R. Suzuki. 2003. Jumyo no chokika ha roujin iryouhi zouka no youinka? [Does longevity cause a rapid rise in medical costs for the elderly?] Kokusai Kokyoseisaku Kenkyu 7 (2): 2-11.

Tauras, J. A., and F. J. Chaloupka. 2001. Demand for nicotine replacement therapies. NBER Working Paper no. 8332. Cambridge, MA: National Bureau of Economic Research, June.

Tsuji, M., and W. Suzuki. 2002. The application of CVM for assessing the telehealth system: An analysis of the discrepancy between WTP and WTA based on survey data. In Assets, beliefs, and equilibria in economic dynamics, ed. C. Aliprantis, K. Arrow, P. Hammond, F. Kubler, H. Wu, and N. Yannelis, 494-506. Berlin, Germany: Springer.

U.S. Department of Health and Human Services. 1988. The health consequences of smoking: Nicotine addiction. A Report of the Surgeon General, 1988. U.S. Department of Health and Human Services, Public Health Service, Center for Disease Control, National Center for Chronic Disease Prevention and Health Promotion, Office on Smoking and Health. DHHS Publication no. (CDC) 888406. Washington, DC: Government Printing Office.

. 1990. The health benefits of smoking cessation. A Report of the Surgeon General, 1990. U.S. Department of Health and Human Services, Public Health Service, Center for Disease Control, National Center for Chronic Disease Pre- 
vention and Health Promotion, Office on Smoking and Health. DHHS Publication no. (CDC) 90-8416. Washington, DC: Government Printing Office.

1995. 21 CFR Pt. 801, et al. Regulations restriction of the sale and distribution of cigarettes and smokeless tobacco products to protect children and adolescents: Proposed rule. Analysis regarding FDA's jurisdiction over nicotinecontaining cigarettes and smokeless tobacco products. Notice. Federal Register 60:155.

1996a. 21 CFR Pt. 801, et al. Regulations restriction of the sale and distribution of cigarettes and smokeless tobacco products to protect children and adolescents: Final rule. Federal Register 61:168.

1996b. Clinical Practice Guideline no. 18: Smoking cessation. Public Health Service, Agency for Health Care Policy and Research, Centers for Disease Control and Prevention. AHCPR Publication no. 96-0692.

Van der Pol, M., and J. Cairns. 1997. Establishing patient's preferences for blood transfusion support: An application of conjoint analysis. Journal of Health Services Research and Policy 3:70-76.

Wasley, M. A., S. E. McNagny, V. L. Phillips, and J. S. Ahluvalia. 1997. The costeffectiveness of the nicotine transdermal patch for smoking cessation. Preventive Medicine 26:264-70.

World Health Organization (WHO). 1993. International classification of diseases. 10 th ed. Geneva, Switzerland: WHO. 
This Page Intentionally Left Blank 